\title{
LOS SEDIMENTOS DEL EMBALSE DE JOAQUÍN COSTA Y LA HISTORIA DE SU DEPÓSITO
}

\author{
A. Navas', B. Valero' ${ }^{1}$ J. Machín ${ }^{1}$ y D. Walling ${ }^{2}$ \\ 1.Estación Experimenta1 de Aula Dei, CSIC, Apdo 202, 50080 Zaragoza. 2. Departamento de Geografía, \\ Universidad de Exeter, Reino Unido.
}

\begin{abstract}
RESUMEN
El embalse de Barasona. cuya cuenca de drenaje está articulada en torno a los ríos Ésera e Isábena, presenta una reducción en su capacidad inicial de almacenamiento de agua como consecuencia del aterramiento. El estudio de los sedimentos acumulados en el vaso permite reconstruir la evolución de su aterramiento y estimar las tasas de erosión. En este trabajo se utilizan técnicas sedimentológicas, mineralógicas, geoquímicas y de radioisótopos trazadores (cesio 137 y plomo 210) para reconstruir la historia sedimentaria del embalse e investigar las áreas fuente de sedimentos, asi como para analizar las variaciones temporales en la tasa de aporte de sedimentos al embalse. Las cronologías establecidas en base a dataciones radioisotópicas muestran una variabilidad espacial y temporal de las tasas de sedimentación en el embalse como consecuencia de la interacción de factores hidrológicos, climáticos, geográficos y técnicos (obras de recrecida del embalse, cambios en el régimen de explotación). Los resultados obtenidos indican que las ivenidas son las principales responsables de la colmatación del embalse, lo cual subraya la importancia del régimen hídrico de los ríos y ha de tenerse en cuenta para el diseño de estrategias de prevención de aterramiento.
\end{abstract}

Palabras clave: aterramiento de embalses, sediinentología. geoquímica, dataciones radioisotópicas

\begin{abstract}
The initial water storage capacity of the Barasona reservir (central Pyrenees) has been reduced since its construction as a consequence of siltation. The study of the deposited sediments allows reconstruction of the siltation history as well as the assessment of erosion rates. In this work a variety of techniques, sedimentological, mineralogical, geochemical and radioisotopic tracers have been used to build up the sedimentary history and to analyse the temporal variations of the sediment supplies. The relative chronologies based on caesiam 137 and lead 210 show both temporal and spatial variability in the sedimentation rates due to the interaction among hydrological, climatic, geographical and technical factors. The results obtained indicate that floods are the main responsible for the siltation in Barasona reservoir and point out the role of the hydric regime of the rivers, aspects that should be bear in mind in order to establish strategies to prevent dam siltation.
\end{abstract}

Key words: reservoir siltation, sedimentology, geochemistry, radioisotopic tracers and chronology.

\section{INTRODUCCIÓN}

La acumulación de sedimentos en los embalses constituye un grave problema para la gestión eficaz de un recurso limitado como el agua. El estudio de estos sedimentos permite reconstruir la evolución del aterramiento, estimar las tasas de erosión media en las cuencas hidrológicas (Sanz et al., 1996; Cobo et al., 1996) e investigar los procesos geomorfológicos (Dearing \& Foster, 1993). El conocimiento de la historia sedimentológica de un embalse es un requisito previo para paliar los problemas de gestión derivados del aterramiento. En este artículo resumimos los resultados del estudio sedimentológico del embalse de Barasona (Fig. 1) y de su cuenca de drenaje de los ríos Ésera e Isábena (Pirineo Aragonés, provincia de Huesca). La capacidad del embalse era de 92 $\mathrm{hm}^{3}$ y se ha reducido en aproximadamente 18 $\mathrm{hm}^{3}$ desde su construcción en 1932 (Fig. 15 del anexo). Mediante estudios batimétricos, se ha calculado el volumen total de sedimentos acumulados y se ha estimado el aporte medio de sedimentos al embalse en $350 \mathrm{t} \mathrm{km}^{-2} \mathrm{año}^{-1}$ (Sanz et al., 1996). Nuestra metodología pretende integrar la historia sedimentaria del embalse y la de la cuenca de drenaje e investigar la heterogeneidad espacial de las áreas fuente de sedimentos en la cuen$\mathrm{ca}$, asi como las variaciones temporales en la tasa de aporte de sedimentos al embalse.

La cuenca de drenaje del embalse de Barasona (1 $224 \mathrm{~km}^{2}$ ) se extiende desde las altas cumbres 


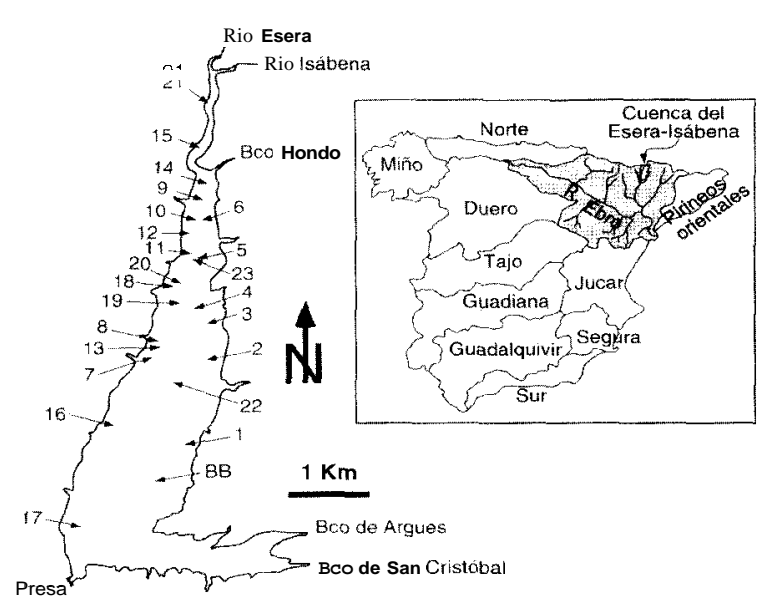

Figura 1. Localización de la cuenca del Ésera - Isábena y mapa del embalse de Barasona con la situación de los sondeos de sedimentos utilizados en este trabajo. Geographical locution of the basin of Esera - Isábena rivers: the Barasona reservoir and core sites.

del Pirineo Central al Norte hasta la sierras prepirenaicas al Sur (Fig. 2). El clima es de montaña, húmedo y frío, con influencias atlánticas y mediterráneas continentales (Ascaso y Cuadrat, 1981). Las precipitaciones varían desde más de $2000 \mathrm{~mm} / \mathrm{año}$ en la cabecera del río Esera hasta menos de $500 \mathrm{~mm}$ en los alrededores del embalse (488 mm/año en la Puebla de Castro). Los mapas de usos del suelo en la comarca de la Ribagorza muestran la heterogeneidad de la vegetación y el impacto humano en la cuenca de los ríos Ésera e Isábena (Manrique et al. (1987) (Fig. 2D).

La cuenca de drenaje del embalse de Barasona está articulada en torno a los ríos Ésera e Isábena. El río Ésera presenta un régimen nival de transición caracterizado por dos máximos y dos mínimos (Marín, 1981). Los caudales máximos ocurren a finales de la primavera y comienzos del verano (fusión de las nieves) y a mitad del otoño coincidiendo con la mayor abundancia de precipitaciones en climas de influencia mediterránea. Los mínimos se producen en invierno (acumulación nival) y verano (menores precipitaciones). El río Isábena tiene un régimen pluvio-nival con dos máximos: uno en el centro de la primavera (abril - mayo) y otro en los meses de otoño; el mínimo se produce en los meses estivales.

Las crecidas muestran una distribución irregular debido al carácter transicional de los regímenes pluviométricos. Las crecidas ocurren a comienzos y finales de primavera y en otoño, pero también en verano debido a fenómenos tormentosos. De acuerdo con el informe del río Esera elaborado para el Plan Hidrológico $\mathrm{Na}$ cional (CHE y MOPTMA, 1993) se han registrado ocho avenidas desde 1892. Las avenidas se asocian a lluvias de comienzos de verano (1925, 1960), tormentas estivales (1963), o mayoritariamente a las lluvias torrenciales otoñales asociadas al fenómeno de la gota fría $(1960,1965,1976$, 1982, 1984).

\section{MATERIAL Y MÉTODOS}

Se han muestreado 21 sondeos y 3 perfiles sedimentarios (B-20, B-21 y B-23) durante varias campañas de campo en los veranos de 1995 y 1996 cuando el embalse estaba prácticamente seco tras las operaciones de vaciado (Fig.1). Se utilizó un sistema dotado de un martillo percutor y una pala retroexcavadora que permite extraer testigos continuos de unos $60 \mathrm{~cm}$ de longitud. El sondeo más largo (BB) se extrajo con un sondeador de pistón fijo tipo Livingstone. Dos sondeos considerados representativos (B-18 y BB) fueron seleccionados para estudios sedimentológicos en detalle. Después de las intensas lluvias del invierno de 1996 se efectuó un muestreo de aguas y sedimentos de la cuenca de drenaje del embalse. Muestras de un litro de agua se tomaron el 28 de Febrero de 1996 a unos $10 \mathrm{~cm}$ del fondo de los ríos y fueron filtradas y pesadas para calcular la concentración de sedimento en suspensión.

Las técnicas de laboratorio utilizadas en el estudio sedimentoiógico de los sondeos son las siguientes:

1) Descripción sedimentológica "de visu".

2) Análisis del contenido en carbonatos (calcimetrías con ácido clorhídrico y valoración con hidróxido sódico) y materia orgánica (calcinación a $550{ }^{\circ} \mathrm{C}$ ).

3) Análisis mineralógico de los sedimentos realizado mediante un difractómetro Siemens D500 , provisto de monocromador de grafito, detector de centelleo y tubo de cobre, trabajando a 40 $\mathrm{Kv}$ y $30 \mathrm{~mA}$.

4) Granuiometrías. Sesenta muestras del sondeo B- 18 fueron seleccionados para determinar su tamaño de grano con un analizador láser de partículas 
Malvern. Setenta muestras del sondeo BB fueron analizadas por un contador de partículas Coulter.

5) Análisis del contenido en cesio 137 y plomo 210. El estudio del contenido en ${ }^{137} \mathrm{Cs}$ de los sedimentos del embalse se realizó en 72 muestras superficiales recogidas por el CEDEX en el vaso del embalse a una profundidad de $\mathrm{SO}$ a $60 \mathrm{~cm}$. La actividad de los radionucleidos ${ }^{210} \mathrm{~Pb}$ y ${ }^{137} \mathrm{Cs}$ fue medida en los sondeos BB (20 muestras, ambos radioisótopos) y B-18 (64 muestras, ${ }^{137} \mathrm{Cs}$ ). El cesio 137 es un radioisótopo de 30 años de vida media, producido como subproducto de las bombas termonucleares en los ensayos atmosféricos realizados entre 1950a 1970. Se distribuyó globalmente en la estratosfera y su depósito comenzó en 19.54, finalizó en 1983 y los picos máximos se alcanzaron entre 1955 y 1966. El uso de esta técnica asume que la incorporación del cesio 137 en el sedimento es rápida y que la migración postdepósito es insignificante (Walling y $\mathrm{He}, 1993$ ). El ${ }^{137} \mathrm{Cs}$ emite rayos gamma en el nivel energético $662 \mathrm{keV}$, que pueden ser fácilmente medidos con un espectrómetro de rayos gamma. Se utilizaron analizadores multicanal conectados a detectores de germanio alojados en contenedores de plomo. Los tiempos medios de conteo oscilaron entre 4 y 8 horas, lo que supone una precisión analítica de +- $6 \%$.

6). Susceptibilidad magnética. La susceptibilidad magnética es una medida compleja que integra diversas interacciones entre la mineralogía del sedimento, el tamaño de grano, las densidades aparente y real y el contenido en carbono orgánico. Las medidas se realizaron con un contador de tipo Bartington MS2 a intervalos de $2 \mathrm{~cm}$. Los cambios en la susceptibilidad magnética informan de las variaciones en el tamaño de grano y en la composición y textura de los sedimentos (Thompson y Olfield, 1986).

\section{RESULTADOS Y DISCUSIÓN}

\section{El registro sedimentario del embalse de Barasona}

\section{Descripción general de los sedimentos}

Para la descripción sedimentológica de los materiales se seleccionaron los sondeos B-18

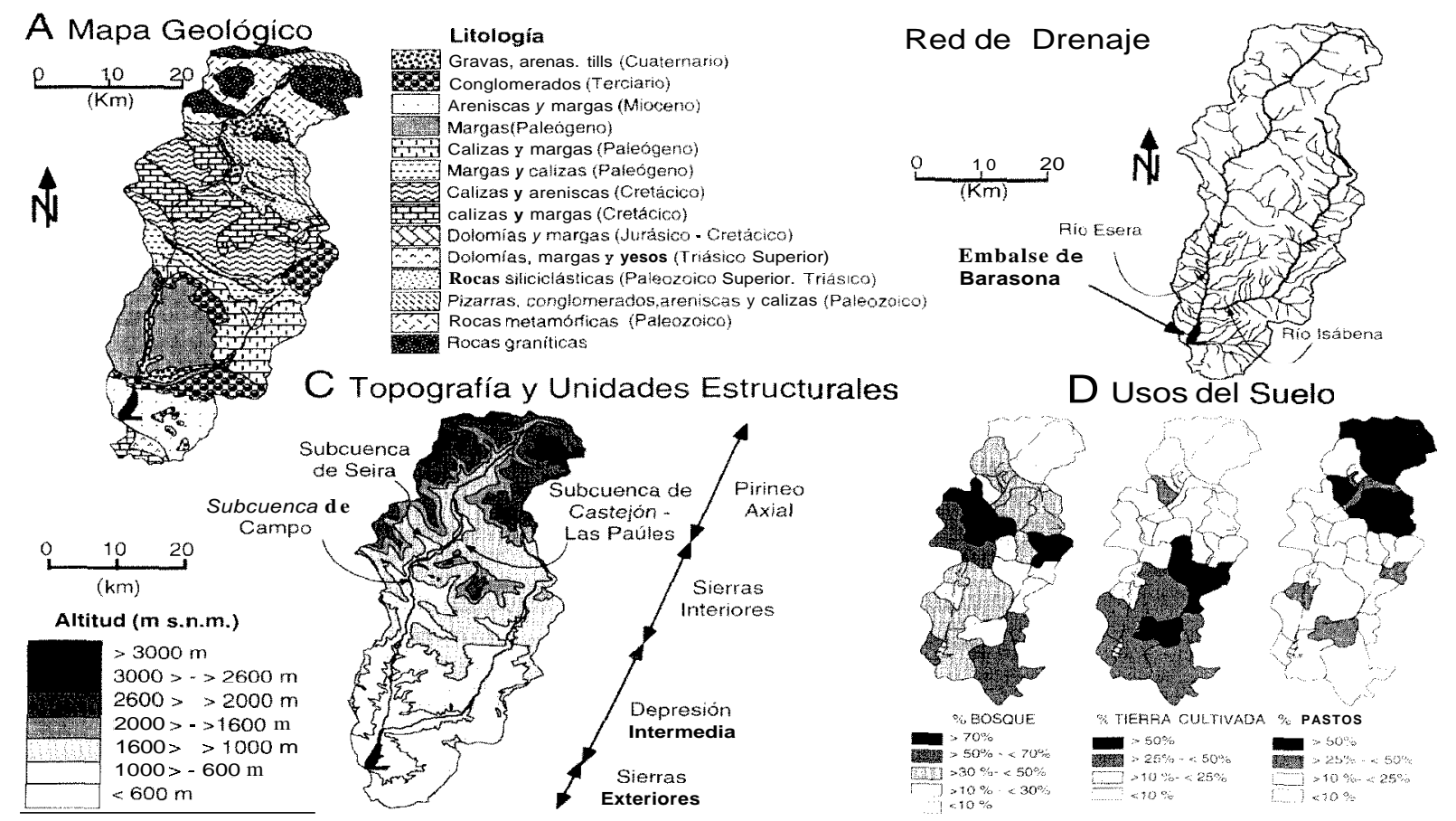

Figura 2. La cuenca del Éscra - Isábena: geología (AL red de drenaje (B), topografía y unidades estructurales (C) y usos del suelo en la cuenca del Ésera - Isábena (D, basado en datos de Manrique et al. 1987). The Esera - Isábena basin: Geology (A), drainage network (B), Topography and structural units (C), land uses ( $D)$ (after Manrique et al. 1987) 
(Fig.3) y BB (Figs. 4 y 6) tanto por su localización en la zona media del embalse como por tratarse de sondeos continuos y el perfil B-21 (Fig. 5), por representar el depósito en la cola del embalse. Los valores medios de la distribución granulométrica de los sedimentos del sondeo B18 (limo, $83.5 \%$; arcilla, $11.5 \%$; arena, 5\%) muestran un dominio de la fracción limo $(90 \%$ del sedimento es menor de $39 \mu$ y el SO \% es menor de $15 \mu$ ). El tamaño medio oscila entre 8 y SO $\mu$ (media $17 \mu$ ) (Fig. 3). La mayoría de los sedimentos se clasifican como limos (> $75 \%$ fracción limo; media $83 \%$ ) y sólo algunas intercalaciones corresponden a limos arenosos (25$40 \%$ fracción arena). El contenido medio en fracción arcilla es del $12 \%$, aunque aumenta en algunos niveles hasta el $20 \%$ (media $12 \%$ ). Los limos finos dominan en el sondeo BB debido a su localización en zonas más alejadas de la desembocadura del Esera (Fig. 4). Las avenidas quedan registradas por capas de granulometría más gruesa (limos gruesos y limos arenosos) y son más frecuentes en la parte superior del sondeo (Fig. 6).

Los sedimentos están compuestos por carbonatos (aprox. 34\%), silicatos (aprox. 60\%) y materia orgánica $(<6 \%)$. La mayoría de los sedimentos se clasifican como limos carbonáticos con detríticos y sólo algunas muestras de limos arenosos corresponden por su composición a limos detríticos con carbonatos (Fig. 7). El contenido en carbonatos, que oscila entre el 25 y el $50 \%$, puede llegar a ser mayoritario en algunos niveles. Los máximos corresponden tanto a facies de limos arenosos como de limos, lo que sugiere que las partículas carbonatadas tienen similar distribución en todas las clases granulométricas. El contenido medio en materia orgánica de los limos del sondeo B-18 es del $3 \%$. Son las facies de limos arenosos las que contienen los valores extremos: menos del $2 \%$ y más del $5 \%$. Estos valores máximos se deben a la presencia de fragmentos vegetales transportados por el río en épocas de avenida, lo que indica que el componente
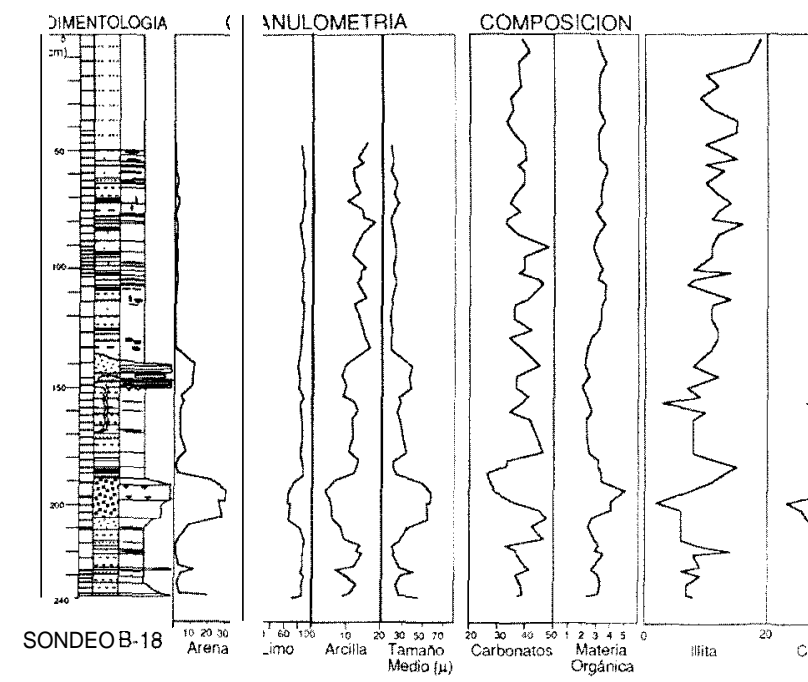

$M \perp N$
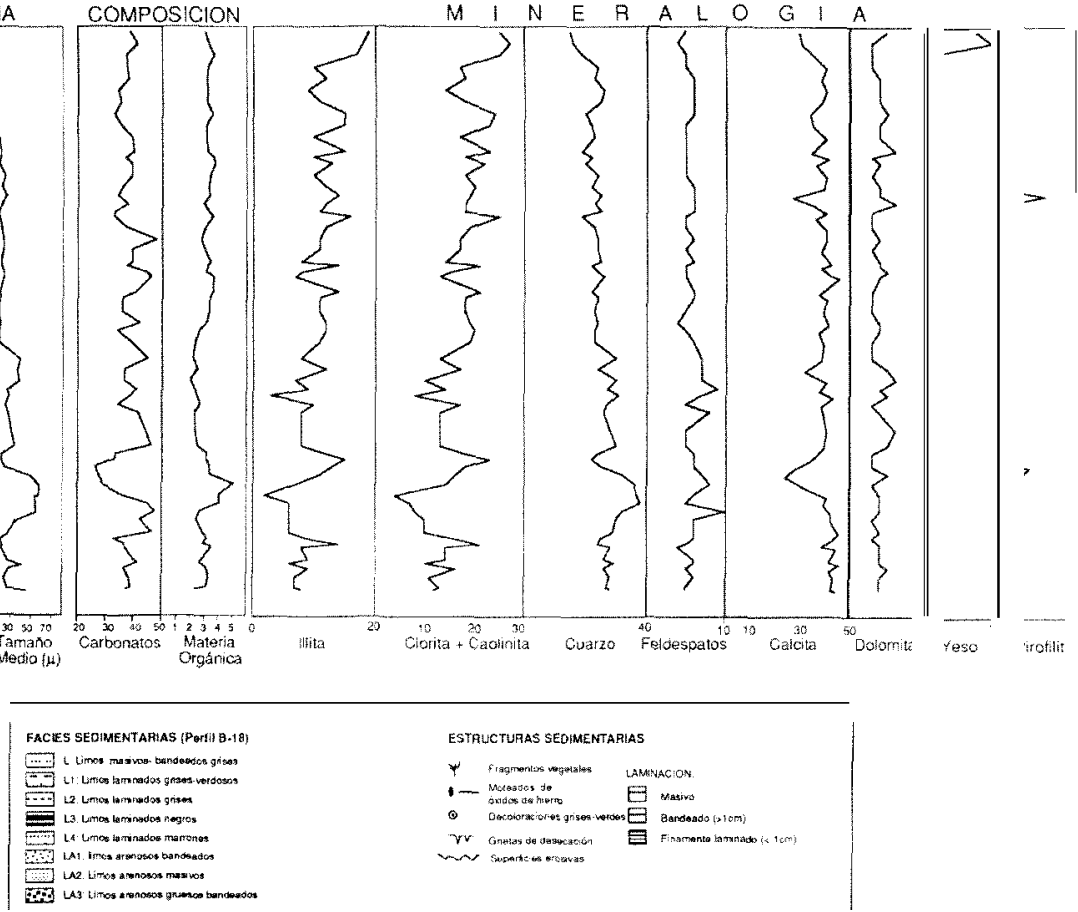

Figura 3. Caracterización sedimentológica, granulométrica, composicional y mineralógica del sondeo B- 18 (sector central del embalse). Sedimentology, granulometry and mineralogy of the B-18core located in the central part of the Barasona reservoir. 


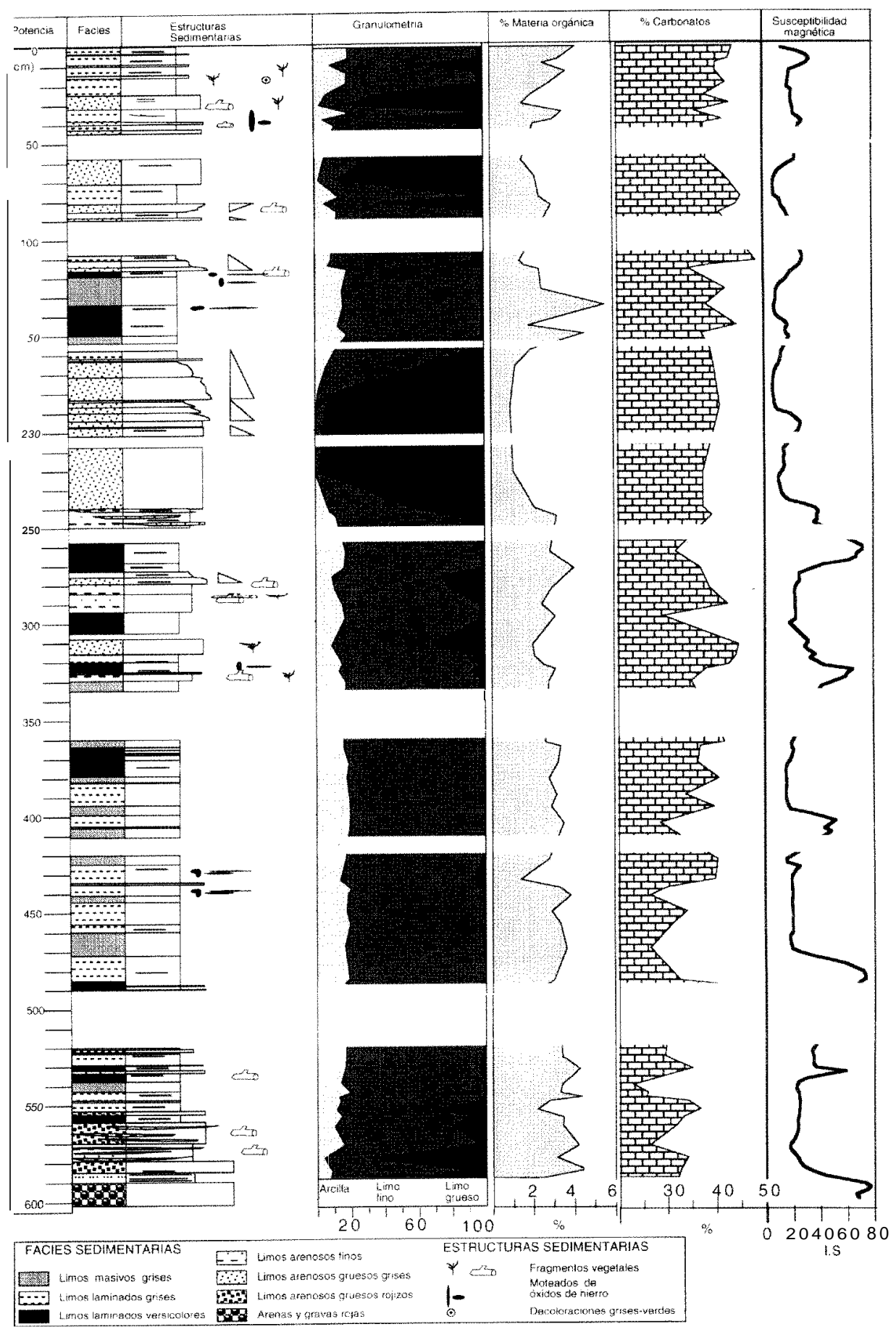

Figura 4. Caracterización sedimentológica, granulométrica, composicional y valores de susceptibilidad magnética del aondeo BB (sector meridional del embalse). Sedimentology, granulometry, magnetic susceptibility und mineralogy of the BB core located in the southern part of the Barasona reservoir. 
alóctono de materia orgánica en los sedimentos es el más importante. En el sondeo BB, los valores máximos de materia orgánica ocurren en los limos masivos grises, igualmente asociados a avenidas.

Los minerales detectados por difracción de rayos $\mathrm{X}$ son: cuarzo, feldespatos, illita, caolinita, clorita, calcita, dolomita, yeso y pirofilita (Figs. 3,5 y 7 ). Los minerales del grupo de los carbonatos (calcita y dolomita) suponen del 30 al $50 \%$ del total; los minerales de la arcilla (cloritas, caolinitas, illitas, pirofilita) entre un $10 \mathrm{y}$ un $40 \%$ y cuarzo y feldespatos entre un 20 y un $40 \%$. La calcita es el mineral mayoritario (39\% media), siempre presente al menos en un $25 \%$ (Figs. 3 y 7 ). Este amplio rango (24-46\%) y su distribución similar en todas las facies confirma que es un mineral alóctono, transportado en granos minerales por los ríos Ésera e Isábena al embalse. La dolomita está en valores generalmente inferiores al 5\%, lo que está de acuerdo con la escasa proporción de dolomías en la cuenca de drenaje. El cuarzo es el siguiente componente mayoritario ( $25 \%$ media; rango: $15-38 \%$ ), y aunque aparece en mayor proporción en las facies de limos arenosos, está presente en todas las fracciones granulométricas. Los filosilicatos del grupo de los minerales de la arcilla (illita, clorita y caolinita) tienen amplios rangos debido a su menor presencia en las facies de granulometría más gruesa $(<5 \%)$ y a su mayor acumulación en los limos finos ( $>$ $15 \%$ en illita y clorita). La caolinita no supera nunca el I $0 \%$. No hay procesos de neoformación de arcillas en el embalse y todos los minerales de la arcilla son igualmente transportados.

Una mención aparte merece la presencia de pirofilita $(3-6 \%$ ) en varios niveles en el sondeo B-18 y también en los B-19, B-20 y B-21. La pirofilita es un mineral con una distribución muy restringida, ya que se trata de un filosilicato índice de metamorfismo de la anquizona o epizona, que se encuentra en pizarras metamorfizadas de bajo grado. No se han realizado estudios en detalle de la composición minera! de los sedimentos paleozoicos en el valle del Esera, sin embargo, trabajos en el Pirineo aragonés occidental (Subias et al., 1990) identifican el Devónico Inferior como Única área fuente. En la cabecera del río Gállego, de toda la serie devónica y carbonífera, sólo un tramo pizarroso a techo del Devónico inferior contiene abundante pirofilita (hasta un 25
$\%$ del total de los minerales de la arcilla). Facies similares a este nivel guía del Pirineo Occidental, aparecen también en la cabecera de los ríos Esera e Isábena (Mey, 1967).Las series pérmicas y triásicas de la cuenca de Las Paúles no contienen pirofilita, con lo que la posible área fuente se restringe a las cabeceras del Esera e isábena donde aflora el Devónico Inferior. Esta restricción geográfica confiere a la pirofilita un carácter de trazador del origen de los sedimentos dentro de la cuenca, confirmada por los resultados preliminares del estudio de los sedimentos presentes en los cauces de los ríos.

El yeso aparece exclusivamente en los niveles superiores del relleno del embalse en el sondeo B-18 (Fig. 3). Debido a su elevada solubilidad, el transporte de partículas de yeso desde suelos yesíferos o afloramientos de formaciones geológicas con yesos (facies Keuper, y facies del Terciario continental) es poco probable. Consideramos que este yeso es autigénico, formado en las pequeñas balsas que quedan en el embalse durante el verano y que son sometidas a una intensa evaporación hasta que desaparecen.

Los valores de susceptibilidad magnética en la mitad superior del sondeo BB (Fig. 4) son menores y con un menor rango de variabilidad. En la parte inferior del sondeo aparecen seis picos relacionados con distintas litologías (limos arenosos, limos laminados o masivos) pero siempre asociados a secuencias sedimentarias granodecrecientes que interpretamos como episodios de avenidas en el embalse. El mayor arrastre de pequeñas partículas de minerales de hierro durante los periodos de avenidas en la cuenca provoca estas desviaciones en la susceptibilidad magnética. El pico inferior corresponde a sedimentos fluviales rojos con abundantes minerales oxidados de hierro.

Las relaciones entre composición mineralógica y granulométrica (Fig. 3) permite diferenciar grupos de variables con comportamientos similares. El cuarzo se correlaciona positivamente con el porcentaje de la fracción arena y negativamente con la fracción arcilla. La illita y la caolinita tienen un comportamiento opuesto al cuarzo, mientras que la clorita y la calcita no muestran correlaciones significativas con ninguna fracción granulométrica. Estas relaciones se deben a que el cuarzo es más abundante en la fracción arena, mientras que las partículas de calcita aparecen en todas las clases granulométricas. 


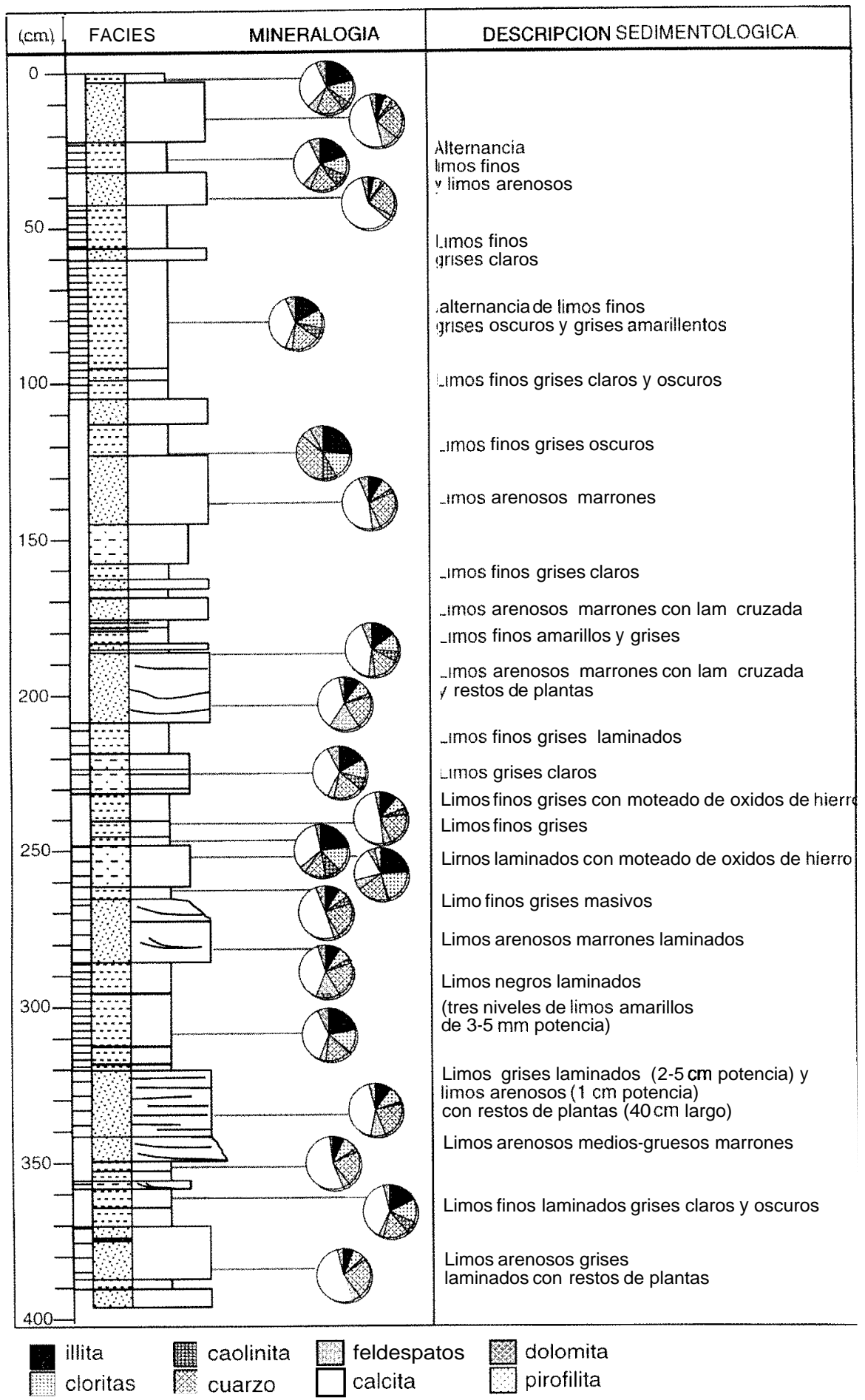

Figura 5. Descripción sedimentológica y composición mineralógica del perfil B-21 (sector del delta de cola del embalse). Sedimentology and mineralogy of the B-2l core located in the northern purt of the Brit-usono reservoir. 
Los minerales de la arcilla (illita, clorita y caolinita) se agrupan entre si y se oponen al grupo formado por el cuarzo y la calcita. Estos grupos responden al diferente comportamiento hidrodinámico de las partículas de cuarzo, calcita y minerales de la arcilla. Los granos de cuarzo, por su mayor tamaño y reducida flotabilidad son transportados dentro del embalse por las corrientes de mayor energía y fundamentalmente por procesos de tracción y carga de fondo; las partículas de calcita aparecen con distintos tamaños y por lo tanto son movilizadas por flujos de diferente capacidad de carga y pueden mantenerse en suspensión por periodos de tiempo más prolongados. Finalmente, la mayoría de las partículas de minerales de la arcilla son depositadas por decantación y por lo tanto se acumulan en las fracciones más finas. La pirofilita aparece en facies con distintas granulometrías pero siempre en niveles con mayor contenido en cloritas.

\section{Facies sedimentarias y modelo sedimentológico.} Facies sedimentarias

En el embalse de Barasona se han definido facies sedimentarias utilizando como criterios el tamaño de grano, contenido en carbonatos y materia orgánica, composición mineralógica, color y estructuras sedimentarias (Figs. 3, 4 y 5). En los 21 sondeos y 3 perfiles estudiados se han definido cinco macrofacies: 1. gravas, arenas y limos rojos; 2. limos rojos con cantos dispersos; 3. conglomerados de cantos blandos limosos; 4. limos arenosos y 5. limos grises (masivos, laminados y versicolores).

1. Las facies de gravas, arenas y limos rojos aparecen en las zonas más litorales del vaso del embalse (sondeos B-8, B-13, B-1) y en la base de algunos sondeos de la zona media (B-7, B-11, B15, B-16 yBB). La composición mineralógica de la fracción arena de estas gravas es similar a la de las arenas que constituyen el relleno del embalse. Estas facies corresponden a depósitos fluviales (terrazas, barras) del río Esera, anteriores a la construcción del embalse.

2. Las facies de limos rojos con cantos dispersos se han encontrado en los sondeos B-7, B-16 y B-17 y se han interpretado como depósitos coluviales procedentes de los materiales detríticos terciarios que limitan el embalse por el oeste. Al igual que las facies de gravas, constituyen el sus-

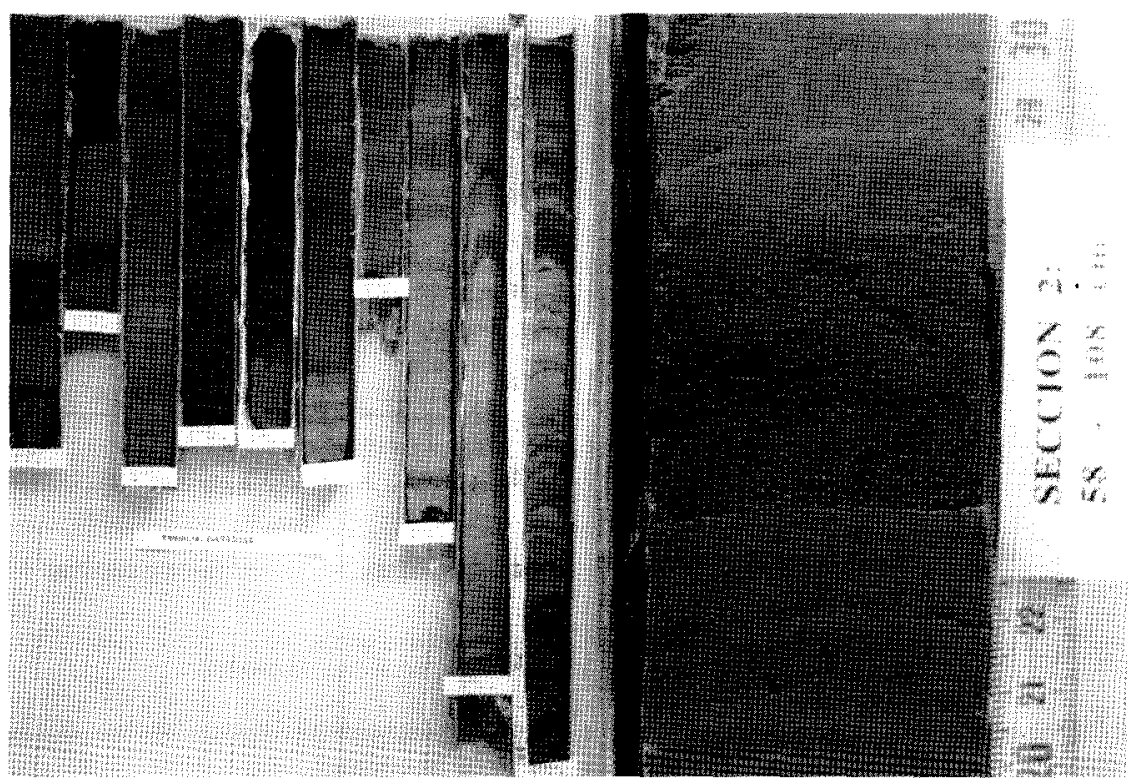

Figura 6. A. El sondeo BB del sector meridional del embalse de Barasona. B. Detalle de una secuencia granodecreciente compuesta de limo arenoso en la base y limos finos a techo que registra una de las avenidas en el embalse de Barasona. A. The BB core in rhe southern purr of the Barasona reservoir: B Detail of un upward fining sequence composed of sandy silt at the base and silt at the lop that was deposited after a flood in the Barasona reservoir: 
trato sobre el que se depositaron los sedimentos limosos propios de la nueva dinámica sedimentaria inaugurada con la construcción del embalse.

3. Los conglomerados de cantos blandos son una facies de distribución restringida (perfil B23) pero de gran interés para comprender la dinámica sedimentaria del relleno del embalse. Aparecen en lentejones de hasta $1 \mathrm{~m}$ de potencia en las cercanías del cauce del Esera y están compuestos por cantos subredondeados y redondeados de 10 - $15 \mathrm{~cm}$ de diámetro y una matriz de limo arenoso o limo. La textura es clasto-soportada y los cantos son de limo consolidado procedente del propio embalse. Estas facies se interpretan como resultado de la erosión de los sedimentos del embalse durante periodos de aguas bajas. La incisión del río Ésera en los sedimentos provoca un talud de varios metros de altura, muy inestable que va desplomándose sobre el cauce del río y proporcionando los fragmentos de limo que son retrabajados. Las partículas más finas serán movilizadas en suspensión hacia áreas cercanas a la presa, mientras que los clastos son arrastrados por el río y forman lentejones conglomeráticos.

4. Las facies de limos arenosos y limos rellenan el vaso del embalse. En el sondeo B-18, los limos arenosos tienen un tamaño medio de $35 \mu$ frente a las $12 \mu$ de los limos y el porcentaje de fracción arena es del $17 \%$ y $<2 \%$ respectivamente. En general, las dos macrofacies son similares en cuanto a componentes mayoritarios, aunque los limos arenosos tienen menos materia orgánica y más carbonatos que los limos (Figs. 3 y 7). Respecto a la mineralogía, los limos arenosos tienen contenidos ligeramente mayores en feldespatos, dolomita y calcita y claramente superiores en cuarzo. Los minerales de la arcilla siempre están en proporciones mayores en los limos. La composición mineral está, por lo tanto, íntimamente ligada a la granulometría: en los limos predomina el transporte en suspensión y el depósito por decantación, con el consiguiente incremento en materiales finos y filosilicatos; en los limos arenosos, el transporte por arrastre de carga de fondo es más importante y de ahí que predominen partículas minerales más gruesas o de menor flotabilidad por sus características hidrodinámicas, como granos subredondeados de cuarzo y carbonatos.

5. Los limos arenosos aparecen en capas de varios decímetros de potencia y capas finas. Las intercalaciones de varios decímetros de potencia comprenden limos arenosos finos, intermedios y gruesos y fueron depositadas por flujos complejos con variaciones temporales en sus parámetros hidrodinámicos (Figuras 4 y 8). Estas facies se interpretan como depósito de avenidas de larga duración (varios días a semanas) en el embalse. Las intercalaciones de menor potencia $(<1 \mathrm{~cm})$ corresponden a limos arenosos intermedios y finos y presentan límites inferiores netos, erosivos, límites superiores graduales a las facies de limos grises y estructura interna granodecreciente. Tanto la reducida potencia como el carácter granodecreciente indican que estos limos se depositaron como resultado de la pérdida paulatina de capacidad de transporte de un único episodio de flujo.

6. Los limos se agrupan en dos subfacies principales: i) limos grises que comprenden capas laminadas y masivas, asi como términos grises y negros; ii) limos laminados versicolores. En el sondeo B-18 hemos caracterizado las propiedades de cuatro subfacies dentro del grupo de los limos que identificamos por el color dominante (Fig. 7): limos verdes (L1), grises (L2), negros (L3) y marrones (L4). En el sondeo BB (Figs. 4 y 7), limos grises masivos y laminados alternan en la parte inferior; estas secuencias se interpretan como depósito en periodos de mayor energía (limos masivos) y menor energía (limos laminados).

\section{Modelo sedimentológico}

1. Subambientes sedimentarios. El embalse de Barasona constituye un ambiente sedimentario en el que predominan los procesos físicos. Los sedimentos son aportados al embalse fundamentalmente en periodos de crecidas o avenidas y redistribuidos con posterioridad. De acuerdo con las características morfológicas y los procesos sedimentarios predominantes hemos distinguido los siguientes subambientes sedimentarios: 1. cola del embalse, 2. deltas de torrentes laterales, 3. fondos del embalse, con diferentes ambientes como la orla litoral, llanura de fondo del valle del Esera, llanura de fondo de la bahía suroriental y canal fluvial del Esera. 4. delta de presa.

1.1. El delta de cola corresponde al depósito formado en las inmediaciones de la desembocadura de los ríos que alimentan un embalse. El delta de cola es un ambiente dominado por los 


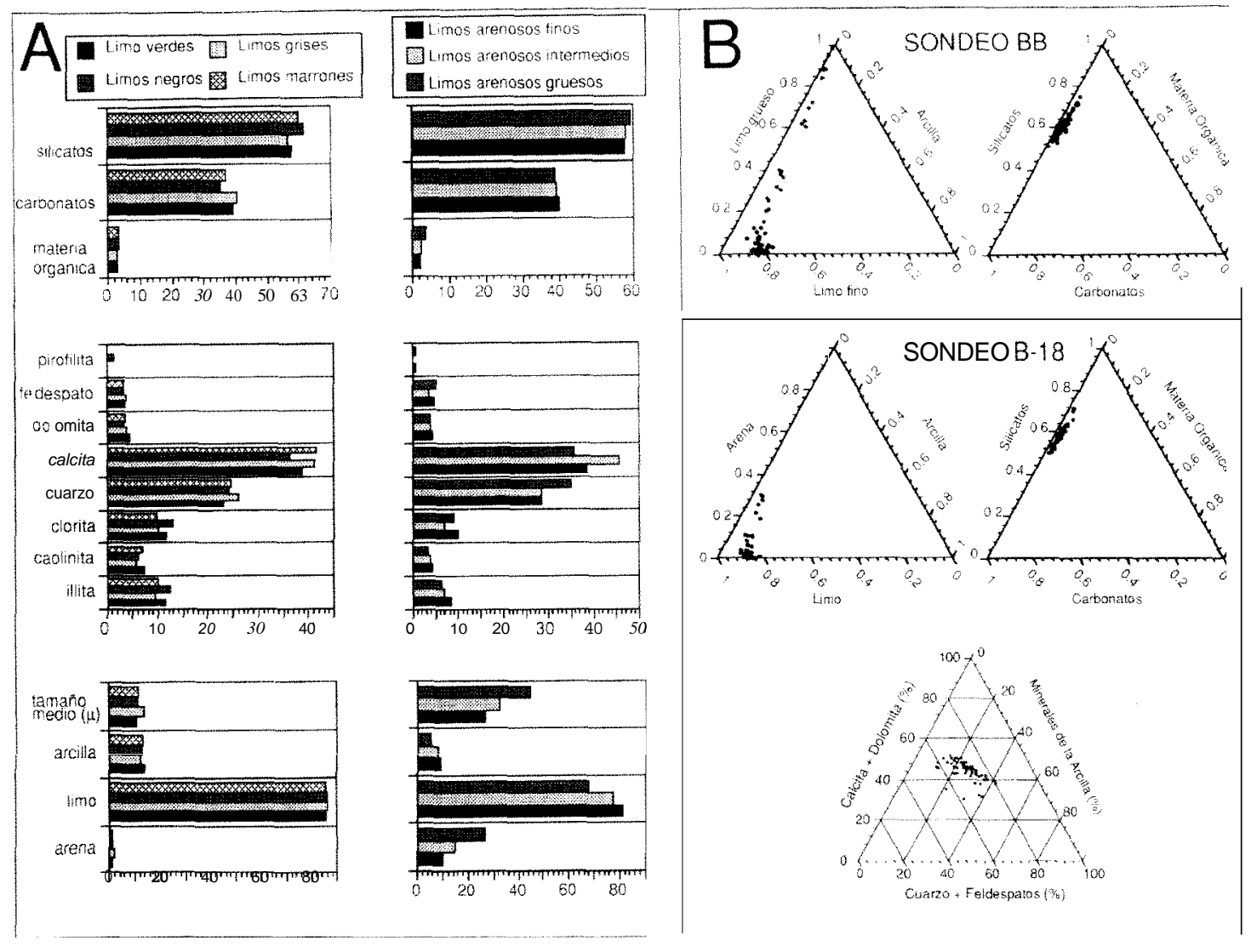

Figura 7. A. Composición mineralógica y granulometría de las distintas facies sedimentarias definidas en el sondeo B-18. B. Diagramas ternarios de composición inedia de los sedimentos de los sondeos B-18 y BB. A. Mineralogical composition and granulometry of the different sedimentary facies in the B-18 core. B Temary diagrams of average sediment composition in the B- 18 and $B B$ cores.

procesos tractivos fluviales en el que los episodios de alta energía (crecidas) quedan marcados por secuencias granodecrecientes complejas. La mayor potencia en este tramo de la cola del embalse se debe a la rápida pérdida de energía experimentada por los flujos fluviales al alcanzar el embalse, con la consiguiente disminución de la capacidad de carga y el depósito del material transportado por arraste y carga de fondo. En Barasona, esta acumulación de sedimentos se localiza desde la desembocadura del Esera en Graus y la confluencia con el Isábena hasta pasada la confluencia con el Barranco Hondo a la altura del cementerio, y constituye, una zona estrecha a ambos lados del cauce del Esera. En el reconocimiento efectuado en el verano de 1995, los sedimentos superficiales del delta de cola eran arenas y limos arenosos, mientras que los limos más finos dominaban en el resto de la superficie del embalse. Más de la mitad de los sedimentos son limos arenosos depositados durante avenidas (perfil B-21, Fig. 5). La potencia del relleno varía desde más de 4 metros en la zona media, pasada la desembocadura del Isábena (perfil B-2 1) hasta menos de 2 metros en la margen derecha del meandro del cementerio (sondeo B-15). Aguas abajo, (sondeos B-14 y B-9) la potencia vuelve a aumentar (>2.5 metros, Fig. 1). Las intercalaciones arenosas en el perfil B-21 son muy numerosas $(5$ de más de $20 \mathrm{~cm}$ de potencia y 8 centimétricas), el porcentaje de arenas mayor y la granulometría de las capas arenosas más potentes es media-gruesa (Fig. 6). Los fragmentos de plantas incluidos en las capas de arenas son decimétricos. 
Las estructuras tractivas (laminación cruzada, granoselección, superficies internas de erosión, etc) son muy comunes tanto en las facies gruesas como finas. Los limos arenosos y arenas tienen menores cantidades de minerales de la arcilla que en las zonas interiores del embalse. Los limos finos, por el contrario, presentan porcentajes similares.

Aguas abajo, el cauce del Ésera dibuja un meandro antes del cementerio. Esta disposición tiene importantes consecuencias sedimentológicas: el perfil B-15 situado en el recodo de la margen derecha del río antes del meandro tiene una potencia acumulada de sedimentos menor (172 $\mathrm{cm})$, las potentes intercalaciones de arenas desaparecen y predominan los limos y limos arenosos. La presencia de una arboleda en esta zona, sin duda también ha contribuido a la pérdida de energía del río. A la salida del meandro, el cauce del Esera se ensancha, lo que provoca un aumen- to del material depositado en los alrededores del cementerio (margen derecha del río, perfiles B14 y B-9). En esta zona, cercana al cauce del Esera, se reconocen cinco intercalaciones arenosas de las sucesivas avenidas (perfil B- 14). Estas capas se acuñan conforme nos alejamos del cauce de manera que solo la más antigua aparece en el perfil B-9, dominado por limos finos.

1.2. Deltas de torrentes laterales. Los torrentes laterales que desembocan en el embalse de Barasona no son muy numerosos y son de régimen esporádico. Su contribución al relleno del embalse no está determinada, aunque puede ser significativa localmente. Durante los periodos de aguas bajas pueden reconocerse lóbulos de sedimentación de pequeños deltas de potencia decimétrica compuestos por limos finos rojizos.

1.3. Fondos del embalse. La mayoria de los sondeos estudiados corresponden al área del embalse situada aguas abajo del delta de cola. Di-

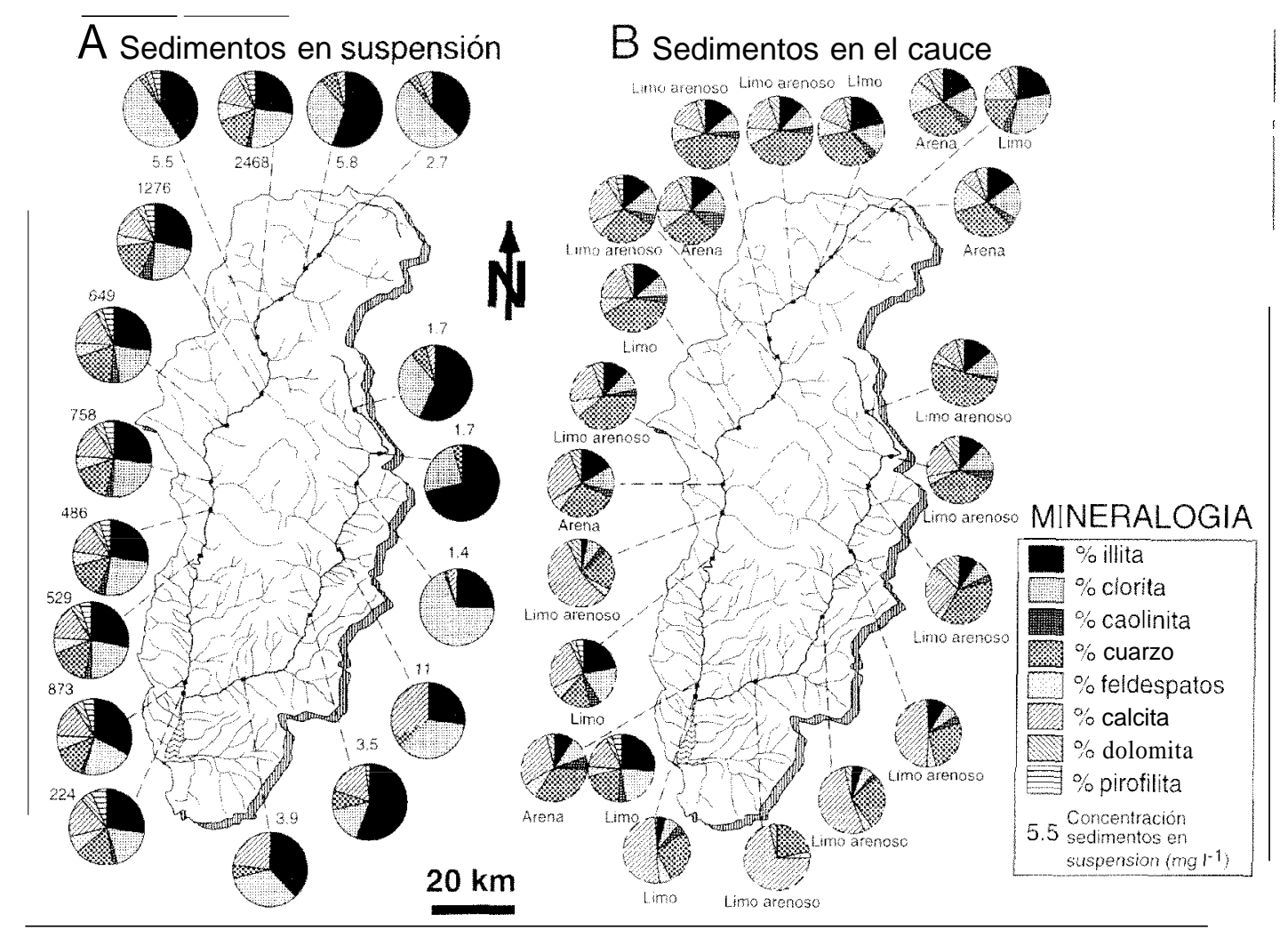

Figura 8. Muestreo de sedimentos en suspensión y en el cauce de los ríos Ésera e Isábena tras un periodo de lluvias intensas en invierno de 1996. Suspended sediments in the Esera and Isábena rivers after intense rainfalls during winter 1996. 
ferenciamos aquí cuatro subambientes sedimentarios: orla litoral, cauce del río y llanura del río Ésera y bahía del barranco suroriental.

1.3.1. La orla litoral. Denominamos orla litoral a la amplia franja alrededor del vaso del embalse en la que el relleno sedimentario es muy escaso (perfiles B-2, B-3, B-4, B-8, B-13 y B-17) o nulo (perfiles B-1, B-16 y B-7). Existe una marcada asimetría entre el depósito sedimentario en la margen derecha (oriental) e izquierda (occidental) del vaso del embalse y también entre la zona septentrional y meridional. En la parte septentrional del embalse, la orla litoral no está muy desarrollada debido al carácter más escarpado de las paredes del vaso y a la menor amplitud del valle del Ésera. La mayoría del fondo del embalse está ocupada por la llanura del Esera con acumulación de sedimentos de varios metros y la orla litoral sólo se reconoce en el margen oriental de morfología menos abrupta.

En la parte meridional del embalse, la orla litoral está más desarrollada debido al ensanchamiento del valle y a la morfología menos escarpada de las paredes del vaso. La asimetría de depósito está causada por la propia asimetría del valle fluvial del Ésera, con el canal del río cruzando en diagonal desde el extremo noroeste al sureste. Esta orla litoral es muy ancha en la margen derecha (perfiles B-17, B-16, B-8, B-13, B7), donde apenas está cubierta por sedimentos del embalse y el sustrato, constituido por gravas fluviales y coluviales, aflora.

Por el contrario, la margen izquierda tiene mayor potencia de sedimentos, especialmente en la zona septentrional (perfiles B-2, B-3, y B-4). Sólo a techo del perfil B-4, el más septentrional, aparecen limos arenosos. El resto del depósito del embalse en esta orla litoral es limoso, lo que indica el predominio del transporte por suspensión y la sedimentación por decantación en los márgenes del embalse.

1.3.2. El cauce del río Ésera. Esta asimetría de la zona litoral y la mayor acumulación de sedimentos siguiendo el eje del curso sumergido del Esera sugiere que el cauce fluvial no es completamente inactivo durante las épocas de aguas altas y que contribuye a canalizar y redistribuir los sedimentos más gruesos. También es un subambiente sedimentario muy activo durante los periodos de aguas bajas. En sucesivos periodos de vaciado parcial del embalse, el río se ha encajado progresivamente en los sedimentos acumu- lados y, como consecuencia, se han formado taludes que en el verano de 199.51legaban hasta los 5 $\mathrm{m}$ de altura. En estos periodos, el Esera es un agente erosivo de los sedimentos del delta de cola e inmediaciones que son canalizados hacia áreas interiores del embalse. Otro aspecto del papel redistribuidor del río se da en conjunción con la inestabilidad de los taludes. Grandes bloques de limos consolidados caen al río y son reducidos a partículas y bloques de menor tamaño y arrastrados a su vez aguas abajo. En las cercanías del puente de piedra sumergido sobre el río Esera (perfil B-23) se han identificado conglomerados de cantos blandos, resultado de estos procesos.

1.3.3. La llanura de fondo del valle del río Esera. Este subambiente sedimentario es el volumétricamente más importante del embalse. Los sedimentos son limos y limos arenosos en su totalidad. Hemos agrupado los sondeos en cuatro sectores: 1. el sector septentrional aguas abajo del meandro del cementerio, 2 . el sector septentrional central en las inmediaciones del antiguo puente de piedra sobre el Esera, 3. el sector central hasta que el canal del Ésera alcanza el margen derecho del valle fluvial y 4 . el sector meridional hasta la zona del barranco de San Cristóbal.

1.3.3.1. El sector septentrional 1 está caracterizado por los perfiles B-6, B-I0 y B-12. Los limos finos constituyen la mayoría del relleno en el área del perfil B-6. Las intercalaciones de limos arenosos son de poco espesor (centimétricas) y probablemente corresponden a los depósitos distales de las avenidas mayores que depositaron arenas en el delta de cola del embalse. Los limos arenosos contienen abundante moteado irregular de óxidos de hierro lo que indica variaciones en las condiciones oxido-reductoras del medio después del depósito. Los cambios en el potencial redox se producirían como consecuencia de la alternancia de periodos de inundación (condiciones reductoras en el sedimento) y exposición subaérea (condiciones oxidantes). Estas zonas septentrionales son las que antes quedan expuestas al bajar el nivel de las aguas del embalse y, consecuentemente, los cambios en las condiciones redox del sedimento son más frecuentes. En la margen derecha del Esera, las capas de limos arenosos son más potentes, especialmente en el perfil más cercano al cauce (B-10). La zona del perfil B-12, más cercana al margen del vaso, sólamente registra las dos intercalaciones arenosas 
superiores (perfiles B-10 y B-12). La granulometría granocreciente de las capas arenosas registradas (150-170, 100-120y $50-75 \mathrm{~cm}$ en el perfil B10 y $75-95$ y $130-140$ en el perfil B-12) podría indicar que las avenidas han sido progresivamente más energéticas.

1.3.3.2. En el sector septentrional 2 los perfiles estudiados, están alejados de la influencia del canal del Esera a ambos lados del antiguo puente y de ahí el predominio de las facies de limos sobre los limos arenosos. El sondeo B-5 en la margen izquierda sólo contiene algunas intercalaciones centimétricas arenosas en los $50 \mathrm{~cm}$ superiores que pueden correlacionarse con las que aparecen en el perfil B-20. El sondeo B-11 alcanzó el sustrato de las gravas del Esera a los 2 metros. A pesar de la cercanía al canal del Ésera, la acumulación de los sedimentos en el área del sondeo B-11 es reducida debido a que un promontorio la resguardaba de la influencia directa de los flujos longitudinales. Se reconocen dos capas de limos arenosos (80-87 y $105-110 \mathrm{~cm}$ ) que pueden correlacionarse con las dos intercalaciones del sondeo B- 12.

1.3.3.3. En la zona central se han descrito dos sondeos (B-18, B-19) y un perfil (B-20). En el perfil descrito en el talud del canal del Ésera (B20) aparecen tres potentes intercalaciones de limos arenosos y numerosas intercalaciones centimétricas potentes en $l o s \quad 60 \mathrm{~cm}$ superiores. En el sondeo B-I9 las intercalaciones de limos arenosos son menos potentes y en el B-18 (Fig. 3) sólo aparecen en la mitad inferior del sondeo: dos decimétricas (facies LA1 y LA2) y dos centimétricas (facies LA3). Las dos capas basales de limos arenosos en los sondeos B-19 y B-20 se correlacionan con la intercalación de limos arenosos de facies LA3 en B-18. Las capas de facies LA 1 (B-18) corresponderían a una potente intercalación en B-20 y a una menos potente en B-19.

Las capas de limos arenosos de la parte superior de los sondeos B-20 y B-19 no aparecen en B-18, pero podrían correlacionarse lateralmente con los niveles de limos grises y verdes en los que el tamaño de grano medio aumenta. La presencia de pirofilita permite precisar más la correlación entre perfiles: los niveles de limos arenosos a $35 \mathrm{~cm}$ en B-20 se corresponden con los limos de la muestra a $30-35 \mathrm{~cm}$ en el sondeo B18. Los dos niveles con pirofilita en el sondeo B-19 a 70 y $85 \mathrm{~cm}$ se correlacionan con los nive- les a $70 \mathrm{~cm}$ en B-18. Los otros dos niveles con pirofilita en el sondeo B- 18 no encuentran equivalente en los sondeos B-19 y B-20, probablemente debido a que la resolución del muestreo es insuficiente.

1.3.3.4. En la zona meridional se han estudiado dos sondeos (B-22 y BB). El sondeo B-22 se compone de una capa basal de limo arenoso con abundantes restos de plantas, una alternancia de limos versicolores laminados y grises bandeados o masivos y otra capa de limos arenosos a techo. El sondeo BB proporciona un registro continuo de casi $6 \mathrm{~m}$, de las condiciones de sedimentación en la zona sur del embalse (Fig. 4). Los limos constituyen la litología más abundante, aunque las capas de limos gruesos son numerosas en la mitad superior del sondeo. En este sector del embalse, las avenidas quedan marcadas por secuencias granodecrecientes compuestas por alternancias de limos masivos y laminados y/o versicolores en la mitad inferior y por limos y limos arenosos en la mitad superior del sondeo. Una potente capa de limos arenosos entre $1.60 \mathrm{y}$ $2.40 \mathrm{~m}$ de profundidad marca el cambio en la dinámica sedimentaria: predominio de limos arenosos y consecuentemente mayores contenidos en carbonatos y disminución de los valores de susceptibilidad magnética. La presencia de estas capas de limos arenosos muestra la elevada capacidad de transporte de las avenidas dentro del embalse. La variabilidad textural de las facies de limos y el predominio de laminación indica que el transporte por tracción sigue siendo prioritario en la zona meridional del embalse cercano al cauce del Ésera.

1.3.4. La bahia suroriental. Esta bahía posee una amplia zona litoral en su extremo más oriental en la que afloran los materiales del sustrato. No disponemos de sondeos del fondo de la bahía, pero dado el carácter esporádico de los torrentes que desembocan en ella, y su situación protegida de la influencia directa del Ésera, ha de esperarse un predominio de los procesos de decantación con el resultado de sedimentación mayoritaria de limos finos.

1.4. El delta de presa. El arrastre de materiales por el cauce del río Esera es el responsable de la acumulación de varias decenas de metros de sedimentos finos en la zona de presa.

2. Procesos sedimentarios. Los procesos de erosión, transporte y sedimentación más impor- 
tantes en el embalse de Barasona están relacionados con los flujos del Ésera. Los sedimentos son aportados al embalse fundamentalmente en periodos de crecidas o avenidas y redistribuidos con posterioridad. En el delta de cola, más de la mitad de los sedimentos son limos arenosos depositados durante avenidas (Fig. 5). El limo que se deposita por decantación en áreas más internas, también ha sido removilizado durante épocas de avenidas. La práctica totalidad del sedimento acumulado es alóctona. La productividad orgánica en el embalse no es conocida, pero una elevada proporción de la materia orgánica acumulada en los sedimentos es también de orígen alóctono.

La dinámica sedimentaria está controlada por las variaciones en las propiedades hidrodinámicas del flujo de ambos ríos a la entrada del embalse. Dos son los parámetros esenciales: 1.- las características del flujo antes de desembocar en el embalse, determinado esencialmente por el caudal que depende a su vez del régimen hídrico estacional de los ríos y 2.- las variaciones en el flujo inducidas por la pérdida de energía al entrar en el embalse con la consiguiente disminución en capacidad de carga. Debido a la morfología elongada Norte- Sur del embalse de Barasona siguiendo el curso sumergido del río Ésera, y a la ausencia de otros cursos de agua significantes que desemboquen en el embalse, la redistribución interna de sedimentos se realiza siguiendo el eje mayor del embalse. La presencia de capas de limos arenosos en el área central (B-22, BB) muestra la elevada capacidad de transporte de las avenidas dentro del embalse e indica que el transporte por tracción sigue siendo prioritario en la zona media del embalse cercano al cauce del Esera. Cuando el embalse se encuentra con una elevada lámina de agua, las arenas y limos arenosos son retenidos en la cola del embalse. Sin embargo, durante los periodos de baja lámina del agua (fines de verano), las avenidas provocadas por tormentas pueden arrastrar sedimentos más gruesos hasta zonas más interiores del embalse.

Los procesos sedimentarios más importantes que suceden en el embalse durante los periodos de exposición subaérea son los siguientes: 1) formación autigénica de yesos; 2) agrietamiento de la superficie de los limos y relleno parcial de las grietas de desecación; 3) transporte eólico en superficie de limos y arenas; 4) incisión del cauce del Esera, caída de bloques en el talud; 5) erosión, transporte y depósito de materiales del embalse por el río Esera (removilización de limos, conglomerados de cantos blandos).

Los procesos químicos autigénicos son de escasa entidad. La precipitación de carbonato en el embalse no ha sido cuantificada, pero no parece una fuente significativa en el caso de Barasona, al contrario de lo que ocurre en otros embalses como el de Puentes donde hasta el SO \% de los carbonatos de las facies de margas han precipitado dentro del embalse (Cobo et al., 1996). Sólamente se ha detectado la formación de yeso durante épocas de exposición subaérea en muy pequeñas cantidades (B-18, Fig. 3) y que son redisueltos. Los procesos diagenéticos más significativos son la compactación física de los sedimentos y la removilización del hierro debido al cambio en las condiciones redox del sedimento.

\section{Los sedimentos de las avenidas del invierno de 1995-96 en los ríos Esera e Isabena}

Las avenidas del invierno de 1995-96 fueron provocadas por un prolongado periodo de lluvias desde Diciembre de 1995 hasta Febrero de 1996. Nuestro muestreo del sedimento acarreado en suspensión no forma parte de una campaña sistemática y los valores obtenidos son meramente indicativos, pero confirman claramente que la mayoría del sediment? en suspensión es aportado al embalse por el río Esera (Fig. 8): los valores a la entrada del embalse son SO veces mayores en el Esera (224 mg/l) que en el Isábena $(3.9 \mathrm{mg} / \mathrm{l})$. La mineralogía de los sedimentos muestreados en el cauce de ambos ríos refleja tanto la granulometría como la heterogeneidad litológica de la cuenca. Los minerales de la arcilla dominan en los sedimentos en suspensión (frecuentemente > $50 \%$ ) en ambos ríos, aunque son relativamente más abundantes en el Isábena debido al menor caudal de este río. En el Esera el cuarzo predomina sobre la calcita y, en general, sucede lo contrario en el Isábena; los feldespatos son más abundantes en el Ésera, como respuesta a la mayor presencia de rocas graníticas en cabecera.

La concentración de sedimento en suspensión, la mineralogía de los sedimentos y las características geológicas permiten diferenciar subáreas de producción de sedimentos en ambas cuencas.

Los bajos valores de sedimento en suspensión en la cabecera del Esera se interpretan como 
resultado de menores tasas de erosión, propias de un paisaje cubierto por la nieve durante el invierno. Por otra parte, más del $50 \%$ del área está cubierta por pastos, que previenen la erosión del suelo a lo largo de todo el año (Ruiz, 1993), y el porcentaje de tierra cultivada es muy pequeño $(<$ 10\%)(Manrique et al., 1987) (Fig. 2D). La pirofilita aparece en las muestras aguas abajo de los barrancos que drenan los afloramientos del Devónico Inferior. Este área queda identificada como única área fuente de este mineral.

En la depresión de Castejón de Sos, los valores del sedimento en suspensión aumentan notablemente $(1276 \mathrm{mg} / \mathrm{l})$ y su composición mineralógica cambia: el cuarzo y la calcita alcanzan hasta un $20 \%$ cada uno. El incremento en superficie cultivada (hasta $50 \%$ ) parece ser el factor desencadente de este aumento en la tasa de emisión de sedimentos. En las cuencas intramontañosas de Seira y Campo la composición del sedimento es similar a la de Castejón, pero los valores decrecen $(650-750 \mathrm{mg} / \mathrm{l})$. El bosque (> $70 \%$ superficie) protege efectivamente el suelo y contribuye a descender los valores de erosión. En el área meridional de la cuenca del Ésera la calcita domina en el sedimento transportado por el río y los valores decrecen relativamente $(<500 \mathrm{mg} / \mathrm{l})$.

La carga en suspensión del río Isábena (hasta $11 \mathrm{mg} / \mathrm{l}$ ) es mucho menor que la del Ésera y la composición mineral muestra el predominio de los minerales de la arcilla y la calcita. La caolinita sólo aparece en los sedimentos del cauce del río y la pirofilita está ausente excepto en una muestra. Distinguimos tres subáreas. La cabecera del Isábena muestra los menores valores de sedimento en suspensión $(1.4-1.7 \mathrm{mg} / \mathrm{l})$ y una mineralogía con muy escaso porcentaje de carbonatos debido a la naturaleza silícea de las rocas aflorantes. El aumento de clorita y dolomita en una muestra responde al afloramiento en las cercanías de dolomías del Jurásico y areniscas y limolitas del Cretácico inferior. Los valores elevados de las áreas medias de la cuenca $(11 \mathrm{mg} / \mathrm{l})$ se correlacionan con un alto contenido en calcita en los sedimentos en suspensión y en la carga de fondo. Finalmente, la carga en suspensión en la parte sur de la cuenca disminuye $(3.5-3.9 \mathrm{mg} / \mathrm{l})$ y el contenido en calcita también. En cuanto a los sedimentos en el fondo del cauce, la calcita claramente predomina en las áreas meridionales del Isábena comparadas con las del Esera, aunque las formaciones geológicas que atraviesan son las mismas. Sin embargo, la presencia de un cambio lateral de facies hacia el este (donde los carbonatos lacustres son más abundantes; Riba, 1972), explicaría estas diferencias.

La correlación entre valores de sedimento en suspensión y los usos del suelo indican que el impacto antrópico ha de considerarse como un factor significativo en la caracterización de subáreas geográficas respecto a su capacidad de emisión de sedimentos. Los valores menores de sedimento en suspensión se dan en áreas con los menores porcentajes de tierra cultivada $(<10 \%)$, importantes porcentajes de cubierta boscosa (50$70 \%$ en la subcuenca de Las Paules y $>70 \%$ en las Sierras Interiores) y los más altos porcentajes de pastos (> 50\%; Figura 3D). Los valores más altos corresponden a las áreas más cultivadas ( $>$ $50 \%$ ) y con menor cubierta boscosa (10-30\%).

\section{Distribución de la actividad del cesio 137 en los sedimentos superficiales en el vaso del embalse}

El contenido en cesio 137 en la muestras de sedimentos superficiales permite analizar la distribución espacial de los sedimentos (Navas y Walling, 1992). En la mayoría de los ambientes, el cesio 137 está fuertemente ligado a los minerales de la arcilla y su redistribución ocurre en asociación con los sedimentos por procesos físicos de erosión o depósito (Navas y Machin, 1991).

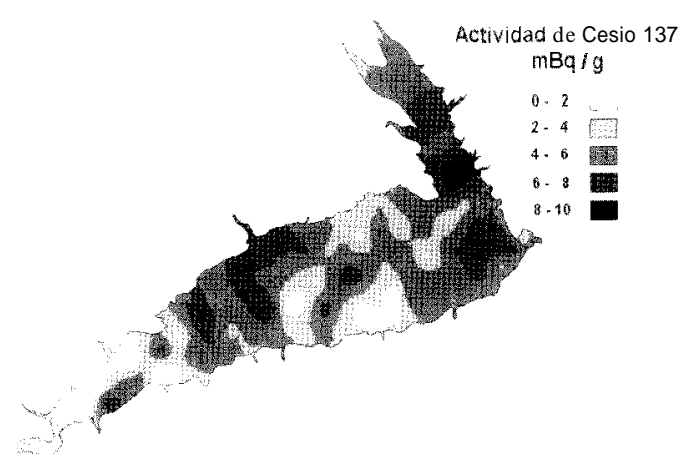

Figura 9. Distribución espacial de la actividad del radionucleido cesio 137 en los sedimentos superficiales del embalse de Barasona. Spatial distribution of the fallout caesiam 137 in the shallow sediments of the Barasona reservoir. 
La actividad de cesio 137, expresada en $\mathrm{mBq} / \mathrm{g}$ se analizó en 72 muestras superficiales del vaso del embalse (Fig. 9). A partir de los datos de actividad de cesio 137 se ha confeccionado un mapa de su distribución mediante interpolación geoestadística (Surfer). La representación espacial de las isolíneas se ha realizado mediante un Sistema raster de Información Geográfica (IDRISI). Los sedimentos superficiales del vaso del embalse tienen unos contenidos de cesio 137 que oscilan de 0.0 a $9.91 \mathrm{mBq} / \mathrm{g}$, lo que evidencia una gran variabilidad espacial. La mayor parte de los sedimentos del embalse presentan contenidos de cesio 137 comprendidos entre 3 y $6 \mathrm{mBq} / \mathrm{g}$. Las actividades mas bajas de cesio 137 se localizan en la cola del embalse correspondiendo con la mayor abundancia de arenas (perfil R-2I, Fig. 5), en las que el contenido del radioisótopo es lógicamente menor como así reflejan sus actividades que son inferiores a $2 \mathrm{mBq} / \mathrm{g}$. Las actividades mas altas predominan en la zona de la presa y en la bahía suroriental, alcanzando un máximo de 10 $\mathrm{mBq} / \mathrm{g}$. Es en estas áreas donde se produce la mayor acumulación de sedimentos arcillosos que tiene su correspondencia con las mayores actividades de cesio 137 del embalse, comprendidas entre 6 a $10 \mathrm{mBq} / \mathrm{g}$. En conclusión, se puede por tanto afirmar que la distribución del radioisótopo muestra una clara correspondencia con las características sedimentológicas del embalse.

\section{Evolución temporal del relleno sedimentario}

De acuerdo con nuestro modelo sedimentológico, las avenidas son las responsables del depósito de capas de arenas y limos arenosos en las zonas del delta de cola y en la parte más septentrional del embalse. La identificación de las capas de arenas más importantes en uno o varios sondeos permite una ordenación temporal relativa de los episodios de avenidas. Nuestra propuesta de cronología relativa se basa en correlacionar las capas de arenas con las avenidas registradas en la cuenca del Esera-Isábena (Fig. 10).

Los datos de caudales instantáneos máximos del río Esera en Villanova, Eriste y Graus y el río Isábena en Capella, permiten identificar las siguientes avenidas principales en la cuenca: Julio y Octubre de 1960; Agosto de 1963; Noviembre de 1965; Octubre y Mayo de 1976; Noviembre de 1982; Noviembre de 1984.La avenida más importante fue la de 1960 (MOPTMA y
CHE, 1993). De todas las capas de arenas identificadas en el perfil B-21, destaca por su mayor potencia, granulometría más gruesa y presencia de fragmentos vegetales decimétricos la situada entre 370-395 cm (Fig. 5). Por lo tanto, tentativamente consideramos que esta capa de arena fue depositada por la avenida de 1960. En la zona del delta de cola cada avenida ha depositado una nueva capa de arena, por lo que es en el perfil B21 donde con más facilidad puede realizarse la adscripción de las sucesivas capas de limos arenosos con las restantes avenidas (Fig. 10).

De acuerdo con esta propuesta de cronología, y teniendo en cuenta su carácter tentativo, la mayor frecuencia de avenidas en la década de los sesenta sería responsable de una elevada tasa de

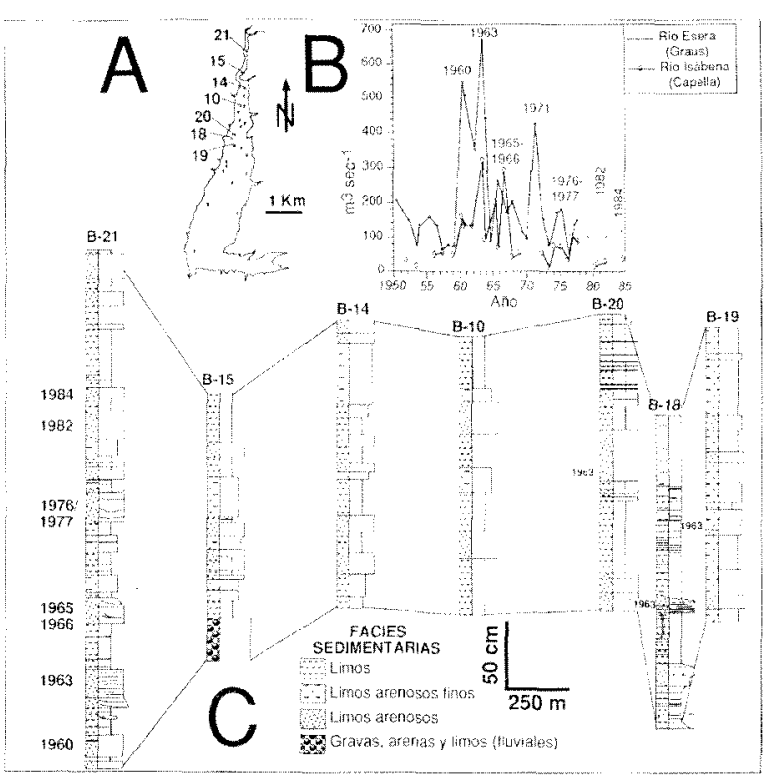

Figura 10. Correlación entre los principales sondeos del delta de cola y sector central del embalse de Baraaona e hipótesis de cronología. Los caudales máximos instantáneos en los ríos Ésera e Isábena en las estaciones de aforo más cercanas al embalse definen las principales avenidas. La capa de limos arenosos más gruesa de la cola del embalse se asigna a la mayor avenida (1960) y las capas suprayacentes correlativamente a las sucesivas avenidas. Relationship between northern cores and central cores si the Barasona reservoir and chronological hypothesis. Instant maximum discharge in rlie Esera arid Isábena control stations define the main floods. The thick sandy silt layer in the northern part of the reservoir is atributed to the major flood occurred in 1960 above this layer the succeeding floods are identified. 


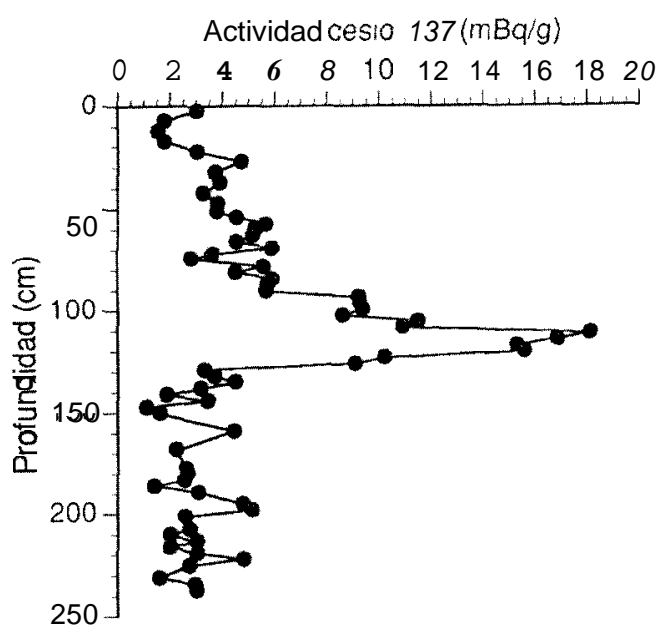

Figura 11. Actividad del radionucleido cesio 137 en el sondeo B18. Fallout caesium 137 in the $B-18$ core.

aporte al delta de cola del embalse $(15 \mathrm{~cm} / \mathrm{año}$; más de $1.5 \mathrm{~m}$ de sedimentos en menos de 10 años); durante los años setenta se produjo una disminución del aporte considerable (menos de $10 \mathrm{~cm} / \mathrm{año}$; menos de $1 \mathrm{~m}$ en una década) y en las últimas décadas se aprecia un aumento sin alcan-

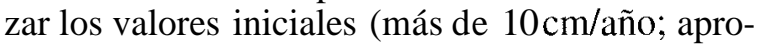
ximadamente unos $1.5 \mathrm{~m}$ en 15 años). Estos valores, sin embargo, no pueden traducirse directamente a cantidades totales de sedimentos transportados al embalse, pues desconocemos la cantidad de material en suspensión aportado por las avenidas.

Las capas de limos arenosos y arenas pueden correlacionarse entre los sondeos del delta de cola y la parte central del embalse. Aguas abajo del delta de cola, la pérdida de energía de los flujos y el acuñamiento de los cuerpos sedimentarios dificulta la correlación. El sondeo B-15 tiene una potencia de sólo $170 \mathrm{~cm}$, pero alcanza el sustrato, por lo que, teóricamente, la secuencia sedimentaria representaría la acumulación desde la construcción del embalse. Las capas de arenas de poco espesor representarían también las sucesivas avenidas. Sin considerar la capa superficial, las restantes capas de limos arenosos en B-14, podrían correlacionarse con las superiores de B21, por lo que el registro sedimentario se extendería hasta la avenida de 1965.En el sondeo B-11
(Fig. 1) también aparece completa la secuencia de depósito del embalse, pero sólo aparecen dos intercalaciones de limos arenosos de difícil asignación temporal.

En el área central, la correlación se dificulta porque los sondeos no contienen el registro completo al no alcanzar el sustrato y, posiblemente, algunas de las capas de limos arenosos se han acuñado o pasado lateralmente a términos más finos. Las capas basales de limos arenosos de los sondeos B- $18(190-210 \mathrm{~cm})$, B-20 $(198-228 \mathrm{~cm})$ y B-19 (205-215 cm) (Figs. 3 y 10) contienen las granulometrías más gruesas de cada sondeo, presentan un porcentaje mayor de cuarzo y restos vegetales de gran tamaño. Estas características sugerirían que se depositaron durante una de las mayores avenidas en el embalse (1960, 1963).

Las cronologías absolutas obtenidas mediante técnicas radiométricas $\left({ }^{137} \mathrm{Cs},{ }^{210} \mathrm{~Pb}\right)$ permiten afinar estas dataciones relativas. La curva de actividad del ${ }^{137} \mathrm{Cs}$ en el sondeo B- 18 muestra valores inferiores a los $5 \mathrm{mBq} / \mathrm{g}$ en la mitad inferior del sondeo, un pico de hasta casi $20 \mathrm{mBq} / \mathrm{g}$ en el intervalo $110-125 \mathrm{~cm}$ (Fig. I 1) y valores descendentes en la parte superior. De acuerdo con la distribución global del radioisótopo, los valores máximos se alcanzaron entre 1955 y 1966 y los picos suelen asignarse a 1954 y 1963, siendo el de 1963 de mayor intensidad. Por lo tanto, si los limos finos del intervalo $110-125 \mathrm{~cm}$ se depositaron en 1963, la capa de arenas inferior $(150 \mathrm{~cm})$ correspondería a la avenida de 1960.En esta zona del embalse, la velocidad media de sedimentación en los Últimos 40 años sería de unos 4 $\mathrm{cm} / \mathrm{año.}$

La curva de actividad del ${ }^{137} \mathrm{Cs}$ en el sondeo $\mathrm{BB}$ presenta una distribución con dos picos entre 471 - 557 y 308 - 391 cm (Fig. 12), cuyos máximos pueden asignarse a los años 1954 (537 - 557 cm) y $1963(375-391 \mathrm{~cm})$. De acuerdo con esta cronología, en este sector del embalse, en las décadas de 1930 y 1940 se depositaron fundamentalmente limos arenosos rojizos, evidenciando que las condiciones de exposición subaérea (aguas bajas) fueron frecuentes. La tasa de sedimentación sería muy baja, $1.5 \mathrm{~cm} /$ año (unos 33 $\mathrm{cm}$ en veinte años). Este hecho podría estar relacionado con el régimen de explotación del embalse que hasta los años 50 utilizaba fundamentalmente los desagües de fondo. La tasa de sedimentación media basada en el pico de 1954 es de 
Actividad Radionucleido (mBq/g)

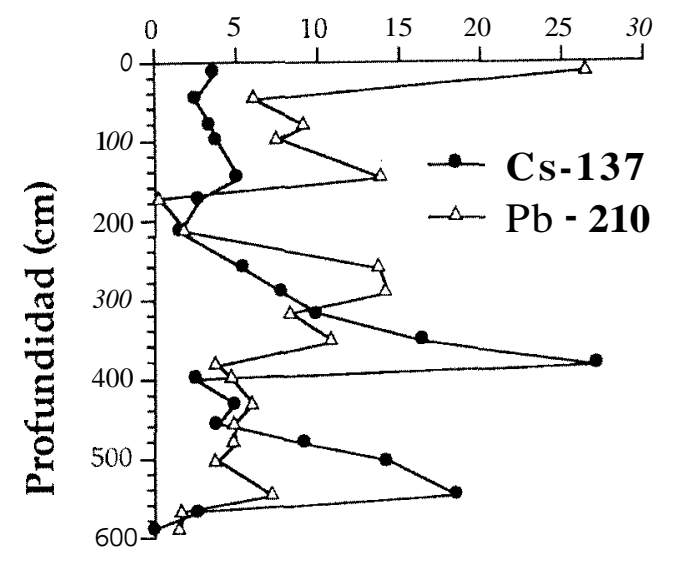

Figura 12. Actividades de los radionucleidos plomo 210 y cesio 137 en el sondeo B B. Lend 210 and caesium 137 depth profiles in the BB core.

13.5 cmíaño. Los dos picos en la actividad del ${ }^{137}$ Cs están separados por $164 \mathrm{~cm}$ lo que indica una tasa de sedimentación entre 1954 - 1963 muy elevada ( $18.2 \mathrm{~cm} / \mathrm{año})$. El predominio de limos finos y la escasez de capas de limos arenosos sugiere que las avenidas durante esta década fueron de menor intensidad o se produjeron durante periodos de aguas altas provocando la acumulación de las arenas en la cola del embalse. Desde 1963 se han depositado casi 4 metros de sedimentos, lo que supone una tasa media de unos $11.6 \mathrm{~cm} /$ año. Esta disminución relativa de la tasa de sedimentación durante las últimas tres décadas ha ido pareja a un cambio en el tipo de sedimentación, con un aumento de las capas de limos arenosos. Este marcado cambio en el tipo de sedimentación puede deberse a cambios hidrológicos (avenidas más frecuentes durante el periodo de aguas bajas en el embalse), meteorológicos (mayor número de eventos extremos), en las condiciones de la cuenca (incremento de la actividad erosiva de los ríos, cambios en el uso del suelo) o en el régimen de explotación del embalse.

Las variaciones en tamaño de grano del sedimento del sondeo BB afectan el contenido en ${ }^{210} \mathrm{~Pb}$ y, por lo tanto, a la fiabilidad de la cronología (Fig. 12). La curva de la actividad del ${ }^{210} \mathrm{~Pb}$ sugiere que las velocidades de Sedimentación han disminuido relativamente en los años recientes, aunque un cambio en el tipo de sedimentación en el embalse (predominio de facies gruesas) podría explicar dichas variaciones.

\section{CONCLUSIONES}

La aplicación de técnicas de análisis sedimentológico de facies a los depósitos del embalse de Barasona y de su cuenca de drenaje ha permitido identificar y caracterizar las facies sedimentarias, correlacionarlas espacialmente, proponer una cronología del relleno y un modelo sedimentológico. La mayor parte del sedimento se transporta al embalse de Barasona durante las avenidas, lo cual subraya la importancia del régimen hídrico de los ríos y ha de tenerse en cuenta a la hora de elaborar posibles estrategias de prevención de aterramiento.

Cronologías relativas basadas en la adscripción de las capas de arenas en el delta de cola a las sucesivas avenidas y absolutas (radioisótopos cesio 137 y plomo 210 ) muestran la variabilidad espacial y temporal de las tasas de sedimentación en el embalse. Las tasas de sedimentación media son mayores en el delta de cola $(10-15 \mathrm{~cm} / \mathrm{año})$ y zona meridional $(11-13 \mathrm{~cm} / \mathrm{anno})$ que en la zona central ( $4 \mathrm{~cm} / \mathrm{año})$. La marcada variabilidad temporal en la tasa de sedimentación responde a la interacción de factores hidrológicos (cambios en el régimen de los ríos), climáticos (variabilidad en la intensidad y distribución de las precipitaciones), geográficos (cambios en las condiciones de la cuenca de recepción) y técnicos (obras de recrecida del embalse, cambios en el régimen de explotación). Nuestros datos indican que la tasa de sedimentación en la zona meridional del embalse fue muy reducida durante las dos primeras décadas de funcionamiento y registró un incremento espectacular a partir de los años cincuenta. El recrecimiento del embalse y los cambios en el régimen de explotación pudieron ser los principales factores desencadenantes. La mayor tasa de aporte al delta de cola del embalse durante la década de los 60 podría ser la respuesta a la mayor frecuencia de avenidas. Mayores tasas de sedimentación durante el periodo 1954 1963 se registran también en el sector meridional. En el delta de cola, durante los años setenta se produjo una disminución del aporte considerable 
y en las últimas décadas se aprecia un aumento sin alcanzar los valores previos. En las zonas más internas del embalse, la tasa de sedimentación parece haber disminuido durante las últimas décadas, paralelamente a un cambio en el tipo de sedimentación, con un aumento de las capas de limos arenosos.

Los cambios en la composición mineralógica de los sedimentos acumulados en el cauce de los ríos Ésera e Isábena proporcionan información sobre áreas fuente de sedimentos. Aunque los factores físicos como topografía, iitoiogía y redes de drenaje ejercen un control esencial en la erosión del suelo, nuestro estudio subraya la importancia de la actividad humana mediante cambios en los usos del suelo. La heterogeneidad de la cuenca en cuanto a la emisión de sedimentos y la variabilidad de la tasa de sedimentación durante las últimas décadas, ilustra la variabilidad de los procesos sedimentarios en una cuenca mediterránea montañosa. Un mejor conocimiento de la variabilidad temporal y espacial de los procesos sedimentarios de erosión, transporte y depósito permite un manejo más adecuado de recursos limitados como suelo y agua y proporcionará estrategias eficaces para aliviar los problemas de aterramiento de embalses.

\section{AGRADECIMIENTOS}

Este trabajo ha sido financiado por un convenio de colaboración entre la Confederación Hidrográfica del Ebro (CEDEX - Ministerio de Fomento y FCC) y la Estación Experimental de Aula Dei del CSIC.

\section{BIBLIOGRAFÍA}

ASCASO, A. y J.M. CUADRAT.1981. El clima. En: Geografía de Aragón. Vol. I. Higueras, A. (ed.):96140. Guara Editorial. Zaragoza.

COBO, R., J.L. GÓMEZ, A. PLATA, M.E. SANZ y C. AVENDAÑO. 1996. Influencia del régimen de explotación del embalse de Puentes en las tasas de sedimentación durante el periodo 1954-1994. Actas V Jornadas Españolas de Presas, Valencia: 155-169.

DEARING, J.A. \& D.L FOSTER. 1993. Lake sediments and geomorphological processes: some thoughts. In: Geomorphology and sedimentology of lakes and reservoirs. J. McManus \& R.W. Duck, (eds.): 5-14. Wiley \& Sons Ltd. N.Y.

FARGAS, D., J.A. MARTÍNEZ \& M.R. POCH. 1996. Identification of critical sediment source areas at regional level. Annales Geophysicae Supplement II to volume 14. European Geophysical Society C 314.

MANRIQUE, E., R. REVILLA y E. SANZ. 1987. Características estructurales del sector agroganadero de la comarca de Ribargorza. Institución Fernando el Católico, Zaragoza. 199 pp.

MEY, P.H.W. 1967. Geology of the Upper Ribagorzana and Baliera valleys, Central Pyrenees, Spain. Leidse Geol. Meded., 41:153-220.

MOPTMA y CHE (1993): Directrices del Plan hidrológico de la cuenca del Ebro. Río Esera. Memoria y Anexos. Zaragoza.

NAVAS, A. \& J. MACHÍN. 1991. A preliminary research on the sue of cesium - 137 to investigate soil erosion in the semiarid landscape of the central Ebro river valley. In: Soil erosion studies in Spain. Sala, M., J.L. Rubio y J.M. García-Ruiz (eds.): 191-202.

NAVAS, A. \& D. WALLING. 1992. Using cesium 137 to assess sediment movement in a semiarid environment in Spain. IAHS Publ. 209: 129-138.

RIBA, O. 1972. Mapa geológico de España E. 1:200 000. Síntesis de la cartografía existente, Hoja de Huesca, IGME. 54 p.

SANZ, M.E., R. COBO y J.L. GÓMEZ. 1995.Modelo de facies del embalse de Puentes, Lorca (Murcia). Comunicaciones XIII Congr. Español de Sedimentología: I65- 166.

SANZ, M.E., R. CORO, C. AVENDAÑO \& J.L. GÓMEZ. 1996. Influence of the drainge basin area on the sediment yield to Spanish reservoirs. First European Conference and Trade Exposition on control erosioa. Sitges (Barcelona), 6 Measuring and modelling erosion processes. $2 \mathrm{pp}$.

SUBIAS, I., C. FERNÁNDEZ-NIETO y J.M. GONZÁLEZ. 1990. Estudio mineralógico de la serie Devónica y Carbonífero Inferior de Sallent de Gállego (Huesca). Boletín de la Sociedad Española de Mineralogía, 13: 183-194.

THOMPSON, R. \& F. OLFIELD. 1986. Environmental magnetism. Allen \& Unwin, Winchester, MA.

VALERO, B.L., A. NAVAS y J. MACHÍN. 1996. Análisis sedimentológico del embalse de Barasona (Huesca). IV Reunion Nacional de Geomorfología. A Coruña, Cadernos Laboratorio Xeoloxico de Laxe 21: 483 - 493.

VALERO. B.L., A. NAVAS \& J. MACHÍN. 1997. Sediment deposition in the Barasona reservoir (cen- 
tral Pyrenees, Spain): temporal and spatial cariability of sediment yield and land use impacts. In: Human Impact on Erosion and sedimentation. Walling, D.E. \& J.L. Probst, (eds.) International Association of Hydrological Sciences Publ. no. 245,: 241- 249.
WALLING, D.E. \& Q. HE. 1993. Towards improved interpretation of ${ }^{137} \mathrm{Cs}$ profiles in lake sediments. In: Ceomorphology and sedimentology of lakes and reservoirs. McManus J. \& Duck, R.W. (eds.): 3154. John Wiley and Sons Ltd. N.Y. 